\title{
Is Topical Antifungal the Appropriate First Choice for Denture Stomatitis?
}

\author{
Isadora Luana Flores, Luiza Teixeira Souza and Ana Paula Neutzling Gomes
}

Department of Dentistry, Federal university in Governador Valadares, Brazil

Corresponding author: Isadora Luana Flores, Adjunct Professor, Department of Dentistry, Federal university in Governador Valadares, Brazil, Tel: +5533999211308; E-mail: isadoraluanaflores@gmail.com

Received: 20 February 2017; Accepted: 26 March 2017; Published: 30 March 2017

Citation: Flores IL, Souza LT, Neutzling Gomes AP. Is Topical Antifungal the Appropriate First Choice for Denture Stomatitis? Ann Clin Lab Res. 5: 1.

\section{Abstract}

Background: Denture stomatitis (DS) is commonly diagnosed during the routine intraoral examination of prosthesis wearers. Episodes of DS relapse occur frequently.

Objective: This study aimed to investigate the therapeutic agents against DS lesions through a briefly review of the English literature on the comparison between topical and systemic protocols.

Materials and methods: A descriptive research was performed on articles published in PubMed/Medline using specific keywords following pre-established inclusion and exclusion criteria.

Results: Only two studies clinically compared topical and systemic protocols for DS treatment.

Conclusion: In vivo comparative studies on topical and systemic antifungal protocols against DS are extremely scarce. Thus, we recommend additional investigations on the drug principles, time of prescription, side effects and the best approach for choosing an antifungal drug. Finally, prosthesis care is a key factor to prevent DS lesions.

Keywords: Stomatitis; Candida; Denture hygiene; Treatment need

\section{Introduction}

Denture stomatitis (DS) is a common type of chronic oral candidiasis. DS clinically appeared as an atrophy of the mucosa restricted to tissue covered by a partial or total prosthesis [1-3]. DS prevalence in prosthesis wearers ranges from $27 \%$ to $65 \%$ [1-3]. Local and systemic predisposing factors account for this type of oral candidiasis.

Critical local risk factors are deficient oral hygiene, nighttime prosthesis wearing, old dentures, prosthesis instability, and traumatism [4-11]. Candida spp., a normal commensal microorganism in oral cavity, can be the pathogenic agent because of the ability to adhere and proliferate through the tissues of oral cavity [2,6-8].

Systemic risk factors related to DS appearance are older age; intake of medications such as anxiolytics, antidepressants, antihypertensive drugs affecting the salivary flow rates, and broad-spectrum antibiotics; diabetes mellitus; nutritional deficiencies and endocrine dysfunctions (hypothyroidism) [9-15].

DS clinical aspects range from small or extensive erythematous dots to granular areas of the mucosa below the denture, generally asymptomatic and located more often on hard palate and alveolar ridge (Figure 1). The English Literature lacks studies emphasizing DS treatment. The association of non-pharmacological methods with antifungal therapy is described as the main therapeutic approach $[16,10]$. Routinely, disinfection of the dental prostheses, renewal of dentures, and the removal of the prosthesis during the night are some of effective non-pharmacological methods $[9,10,17,18]$. Topical antifungal therapy is the widely prescribed protocol; systemic antifungal use is extremely rare, only in cases of recurrent DS $[1,17,19,20]$. However, failure and/or relapse is a daily event during topical antifungal therapy.

Thus, the dentists routinely face the clinical dilemma of selecting the correct antifungal therapy to treat DS. Therefore, this study aimed to investigate the therapeutic agents against DS through a briefly review of the English literature on the comparison between topical and systemic protocols.

\section{Material and Methods}

The descriptive review was performed based on articles searched in PubMed/Medline. The keywords selected were "oral candidiasis, chronic atrophic candidiasis, denture stomatitis, prosthesis, topic and systemic antifungal treatment". The inclusion criteria were (1) articles published in English language; (2) experimental and/or review studies focusing on treatment of denture stomatitis; (3) in vivo comparative studies involving topical and systemic antifungal therapy against DS. The exclusion criteria were (1) manuscripts in other languages; (2) articles with no access to full text; (3) studies with no focus on DS treatment or on the comparison between the topical and systemic drugs (4) case reports. A 
complete reading of the included articles was performed and the main results were discussed.

\section{Results}

Considering the proposed keywords, eight studies on antifungal DS treatment were found. The number was reduced to two articles after strictly applying the inclusion criteria $[1,21]$. Of the eight articles, one study was not written in English, the full text of 4 articles was not available [18,22-24] and 6 articles did not fulfill the review subject (DS diagnosis and/or the comparison between topical and systemic antifungal protocols) [17,19,22-24]. A complete list of all revised manuscripts is showed in Table 1.

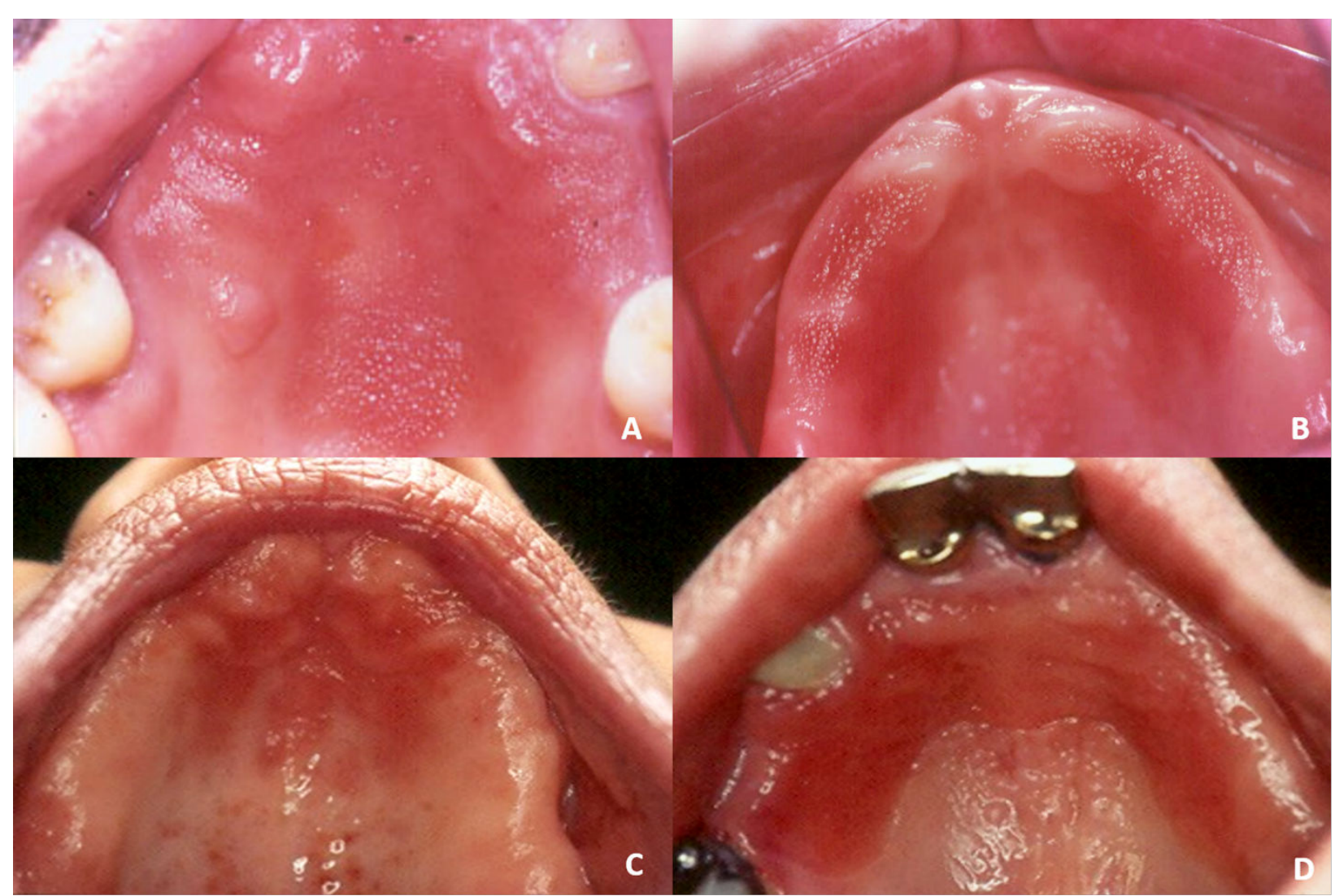

Figure 1 Sequence of clinical aspects of denture stomatitis. Extensive erythematous area on the hard palate and maxillary alveolar ridge (A). Bilateral erythematous aspect on the maxillary alveolar bridge extending towards anterior hard palate (B). Erythematous area on the palate; observe the dotted aspect on the posterior hard palate (C). A marked bilateral erythematous area on the maxillary alveolar bridge up to hard palate. Note that this area matched the same site of mucosa covered by removable prosthesis (D). The discreet granular aspect can be observed on the surface of all lesions.

Table 1 Complete list of reviewed articles on denture stomatitis (DS) and antifungal treatment.

\begin{tabular}{|c|c|c|c|c|}
\hline Author & Year & Type of Study & Therapeutic Antifungal protocol & Main Result \\
\hline Haessler & 1978 & Experimental research & Topical Clotrimazole & $\begin{array}{l}\text { Improvement followed by recurrence after drug } \\
\text { suspension }\end{array}$ \\
\hline Bissel et al. & 1993 & Experimental research & $\begin{array}{l}\text { Systemic fluconazole } 50 \mathrm{mg} X \\
\text { Amphotericin lozenges and cream }\end{array}$ & $\begin{array}{l}\text { Similar clinical results, uncommon side effects and } \\
\text { recurrence for both treatments }\end{array}$ \\
\hline Banting et al. & 1995 & Experimental research & $\begin{array}{l}\text { Topical liquid nystatin } 100,000 \\
\mathrm{IU} / \mathrm{mL} \text { associated with nystatin } \\
\text { vaginal lozenge } 100,000 \mathrm{IU} / \mathrm{g} \times \mathrm{Tap} \\
\text { water }\end{array}$ & $\begin{array}{l}\text { Reduction of recurrence rate of clinical signs and } \\
\text { symptoms }\end{array}$ \\
\hline Salonen et al. & 1996 & $\begin{array}{l}\text { Experimental research } \\
\text { (case-control study) }\end{array}$ & $\begin{array}{l}\text { Topical miconazole } 2 \% \text { gel } X \\
\text { Systemic fluconazole } 50 \mathrm{mg}\end{array}$ & $\begin{array}{l}\text { Positive results for both regimens with better } \\
\text { findings for systemic antifungal }\end{array}$ \\
\hline Muzyka & 2005 & Literature review & $\begin{array}{l}\text { Antifungal medications commonly } \\
\text { used by dentists }\end{array}$ & $\begin{array}{l}\text { Topical medications are the first line of therapy } \\
\text { Disinfection of the dental prostheses during the }\end{array}$ \\
\hline
\end{tabular}




\begin{tabular}{|c|c|c|c|c|}
\hline & & & & $\begin{array}{l}\text { treatment to avoid reinfection. Systemic therapy is } \\
\text { applied in resistant cases that donot respond to } \\
\text { topical therapy }\end{array}$ \\
\hline Milillo et al. & 2005 & Experimental research & $\begin{array}{l}\text { Topical varnish containing } 5 \% \\
\text { amorolfine }\end{array}$ & The varnish suppressed the nystatin resistance \\
\hline Koray et al. & 2005 & Experimental research & $\begin{array}{l}\text { Systemic fluconazole } 50 \mathrm{mg} X \\
\text { Hexetidine mouthrinses } 1 \% \times \\
\text { Fluconazole } 50 \mathrm{mg} \text { plus hexetidine } \\
\text { mouthrinses }\end{array}$ & $\begin{array}{l}\text { No statistically significant difference was observed } \\
\text { among the regimens. Hexetidine presented fewer } \\
\text { side effects }\end{array}$ \\
\hline Khozeimeh et al. & 2010 & Experimental research & $\begin{array}{l}\text { Systemic ketoconazole tablet } 200 \\
\text { mg X Topical ketoconazole } 2 \% \text { in } \\
\text { orabase }\end{array}$ & $\begin{array}{l}\text { Topical ketoconazole } 2 \% \text { in orabase had efficacy } \\
\text { similar to ketoconazole tablet and fewer side effects }\end{array}$ \\
\hline
\end{tabular}

\section{Discussion}

Because of the high relapse rates of classical topical antifungals, we hypothesized which antifungal protocol would be better for DS treatment $[25,26]$. According to the inclusion criteria, only two study trials on patients with DS focused on the treatment with topical and systemic antifungal [1]. One study observed similar efficacy between topical and systemic antifungals using two forms of ketoconazole: orabase (topical) and tablet (systemic) [1]. At long-term administration, the ketoconazole tablet produced more side effects than topical ketoconazole, including gastrointestinal disturbances such as nausea, vomiting, diarrhea, constipation, and abdominal pain [1]. Also, these studies observed transient elevation of liver serum enzymes, hepatitis, adrenal cortex suppression, pruritus, rash, headache, dizziness, and somnolence $[1,27]$. Likewise, the comparison of amphotericin lozenges and topical cream with systemic fluconazole showed similar clinical response [21]. However, either uncommon or no side-effects occurred during the treatment with fluconazole and only one patient complained about nausea [21]. Thus, the administration of both topical and systemic antifungals showed positive results for DS treatment. From a clinical point of view, although the literature reports small number of side effects with fluconazole, the results observed in only two studies did not allow us to draw conclusions on side effects.

In the dental clinical routine, the polyene agents (including nystatin) are the most topical agent prescribed for patients with DS [17]. Systemically, Azole antifungals (ketoconazole and fluconazole) are the drugs most used [28-34]. Systemic therapy has been prescribed for DS in cases not responding to topical agents or in cases with presence of systemic factors, such as immunosuppression or diabetes [35-37]. Generally, the dentists are concerned about prescribing systemic antifungals because of the risk of side effects. 36 Conversely, in vivo studies reported the efficacy of systemic antifungals with minimal or no side effects to treat patients with DS through $[1,21,25,38]$. Interestingly, a Spanish study on drug choice for oral candidiasis demonstrated the strong predilection for topical drugs (miconazole and nystatin) by general dentists while the experts, including stomatologists frequently chosen systemic antifungals in the same cases [16]. Therefore, the stomatologists' knowledge on time administration and side effects and large expertise in oral medicine led them to choose systemic antifungal.
Despite the availability of a number of antifungal drugs, the DS relapse after antifungal therapy is often noticed $[21,23,26]$. Nystatin is the first treatment choice for DS, but some articles reported lack of DS cure and yeasts recolonization after cessation of drug protocol $[39,21]$. A possible cause of the lesion relapse would be the persistence of Candida biofilms on the mucosa and on inert prosthesis surfaces [21]. Moreover, multiple daily doses for a relatively long period have been associated with lower patient compliance, immunodeficiency, and drug resistance, which are additional factors against complete recovery [26]. The aspects associated with the prosthesis, including poor hygiene, habit of sleeping with prosthesis, and no replacement of old prostheses play a role in the lesion relapse, regardless of DS treatment type.

\section{Conclusion}

Due to the high DS relapse frequency, in vivo comparative studies on topical and systemic antifungals are urgently required to evaluate the efficacy, advantages, and disadvantages related to both protocols. To the best of our knowledge, this present short review was the first study to search this topic aiming to reach some reliable conclusions and guide the dentists during the choice for antifungals. The few studies on this topic limited our assumptions. Nevertheless, we recommend further studies on the drug principles, time of administration, side effects, and best practice to choose an antifungal drug. Finally, prosthesis care is a key strategy for the complete healing of DS lesions.

\section{References}

1. Khozeimeh F, Shahtalebi MA, Noori M, Savabi O (2010) Comparative evaluation of ketoconazole tablet and topical ketoconazole $2 \%$ in orabase in treatment of Candida-infected denture stomatitis. J Contemp Dent Pract 11: 17-24.

2. Budtz-Jörgensen E (1974) The significance of Candida albicans in denture stomatitis. Scand J Dent Res 82: 151-190.

3. Budtz-Jörgensen E (1981) Oral mucosal lesions associated with the wearing of removable dentures. J Oral Pathol 10: 65-80.

4. Zissis A, Yannikakis S, Harrison A (2006) Comparison of denture stomatitis prevalence in 2 population groups. Int J Prosthodont 19: 621-625.

5. Figueiral $M H$, Azul A, Pinto E, Fonseca PA, Branco FM, et al. (2007) Denture-related stomatitis: Identification of aetiological 
and predisposing factors: A large cohort. J Oral Rehabil 34: 448-455.

6. Budtz-Jörgensen E, Stenderup A, Grabowski M (1975) An epidemiologic study of yeasts in elderly denture wearers. Community Dent Oral Epidemiol 3: 115-119.

7. Altarawneh S, Bencharit S, Mendoza L, Curran A, Barrow D, et al. (2013) Clinical and histological findings of denture stomatitis as related to intraoral colonization patterns of Candida albicans, salivary flow, and dry mouth. J Prosthodont 22: 13-22.

8. Bilhan H, Sulun T, Erkose G, Kurt H, Erturan Z, et al. (2009) The role of Candida albicans hyphae and Lactobacillus in denturerelated stomatitis. Clin Oral Investig 13: 363-368.

9. Salerno C, Pascale M, Contaldo M, Esposito V, Busciolano M, et al. (2011) Candida-associated denture stomatitis. Med Oral Patol Oral Cir Bucal 16: e139-143.

10. Gendreau L, Loewy ZG (2011) Epidemiology and etiology of denture stomatitis. J Prosthodont 20: 251-260.

11. Webb BC, Thomas CJ, Willcox MD, Harty DW, Knox KW (1998) Candida-associated denture stomatitis. Aetiology and management: A review. Part 2. Oral diseases caused by Candida species. Aust Dent J 43: 160-166.

12. Jainkittivong A, Aneksuk V, Langlais RP (2010) Oral mucosal lesions in denture wearers. Gerodontology 27: 26-32.

13. Lynge Pedersen AM, Nauntofte B, Smidt D, Torpet LA (2015) Oral mucosal lesions in older people: Relation to salivary secretion, systemic diseases and medications. Oral Dis 21: 721-729.

14. Martori E, Ayuso-Montero R, Martinez-Gomis J, Viñas M, Peraire $M$ (2014) Risk factors for denture-related oral mucosal lesions in a geriatric population. J Prosthet Dent 111: 273-279.

15. MacFarlane TW, Samaranayake LP (1989) Fungal infections. In: Clinical Oral Microbiology. London: Wright 122-139.

16. Martínez-Beneyto $Y$, López-Jornet $P$, Velandrino-Nicolás $A$, Jornet-García V (2010) Use of antifungal agents for oral candidiasis: Results of a national survey. Int J Dent Hyg 8: 47-52.

17. Muzyka BC, Epifanio RN (2013) Update on oral fungal infections. Dent Clin North Am 57: 561-581.

18. Salonen MA, Raustia AM, Oikarinen KS (1996) Effect of treatment of palatal inflammatory papillary hyperplasia with local and systemic antifungal agents accompanied by renewal of complete dentures. Acta Odontol Scand 54: 87-91.

19. Koray M, Ak G, Kurklu E, Issever $H$, Tanyeri $H$, et al. (2005) Fluconazole and/or hexetidine for management of oral candidiasis associated with denture-induced stomatitis. Oral Dis 11: 309-313.

20. Garcia-Cuesta C, Sarrion-Pérez MG, Bagán JV (2014) Current treatment of oral candidiasis: A literature review. J Clin Exp Dent 6: 576-782.

21. Bissell V, Felix DH, Wray D (1993) Comparative trial of fluconazole and amphotericin in the treatment of denture stomatitis. Oral Surg Oral Med Oral Pathol 76: 35-39.

22. Haessler D (1978) Local and systemic antimycotic therapy of Candida-induced denture stomatitis. Dtsch Zahnarztl Z 33 372-374.

23. Banting DW, Greenhorn PA, McMinn JG (1995) Effectiveness of a topical antifungal regimen for the treatment of oral candidiasis in older, chronically ill, institutionalized, adults. J Can Dent Assoc 61: 199-200.

24. Milillo L, Lo Muzio L, Carlino P, Serpico R, Coccia E, et al. (2005) Candida-related denture stomatitis: A pilot study of the efficacy of an amorolfine antifungal varnish. Int J Prosthodont 18: 55-59.

25. Anibal PC, de Cássia Orlandi Sardi J, Peixoto IT, de Carvalho Moraes JJ, Höfling JF (2010) Conventional and alternative antifungal therapies to oral candidiasis. Braz J Microbiol 41: 824-831.

26. Chandra J, Mukherjee PK, Leidich SD, Faddoul FF, Hoyer LL, et al. (2001) Antifungal resistance of candidal biofilms formed on denture acrylic in vitro. J Dent Res 80: 903-908.

27. Greenberg M, Glick M, Ship JA (2008) Burket's oral medicine, (11thedn). Hamilton, Ontario: BC Deeker 81-84.

28. Dar-Odeh NS, Al-Beyari M, Abu-Hammad OA (2012) The role of antifungal drugs in the management of denture: Associated stomatitis. Int J Antimicrob Agents 2: 1-5.

29. Neppelenbroek KH, Pavarina AC, Palomari DM, Sgavioli Massucato EM, Spolidorio LC, et al. (2008) Effectiveness of microwave disinfection of complete dentures on the treatment of Candida-related denture stomatitis. J Oral Rehabil 35: 836-846.

30. Bergendal T, Isacsson $G$ (1980) Effect of nystatin in the treatment of denture stomatitis. Scand J Dent Res 88: 446-454.

31. Blomgren J, Berggren U, Jontell M (1998) Fluconazole versus nystatin in the treatment of oral candidosis. Acta Odontol Scand 56: 202-205.

32. Kulak Y, Arikan A, Delibalta N (1994) Comparison of three different treatment methods for generalized denture stomatitis. J Prosthet Dent 72: 283-288.

33. Sanitá PV, Machado AL, Pavarina AC, Massucato EM, Colombo $A L$, et al. (2012) Microwave denture disinfection versus nystatin in treating patients with well-controlled type 2 diabetics and denture stomatitis: A randomized clinical trial. Int J Prosthod 25: 232-244.

34. Silva MM, Mima EG, Colombo AL, Sanitá PV, Jorge JH, et al. (2012) Comparison of denture microwave disinfection and conventional antifungal therapy in the treatment of denture stomatitis: a randomized clinical study. Oral Surg Oral Med Oral Pathol Oral Radiol 114: 469-479.

35. lacopino AM, Wathen WF (1992) Oral candidal infection and denture stomatitis: a comprehensive review. J Am Dent Assoc 123: 46-51.

36. Chow CK, Matear DW, Lawrence HP (1999) Efficacy of antifungal agents in tissue conditioners in treating candidiasis. Gerodontology 16: 110-118.

37. Udita SM, Karthik KS, Sudhakara VM (2010) Candidiasis in Denture wearers: A Literature Review. JIADS 1: 27-30.

38. Cross LJ, Bagg J, Wray D, Aitchison T (1998) A comparison of fluconazole and itraconazole in the management of denture stomatitis: A pilot study. J Dent 26: 657-664.

39. Bergendal T, Isacsson $G$ (1980) Effect of nystatin in the treatment of denture stomatitis. Scand J Dent Res 88: 446-454. 